\title{
ANALISIS PERILAKU SOLUSI MODEL GERAK AYUNAN YANG DIPENGARUHI GAYA GESEKAN YANG BERBANDING LURUS DENGAN KECEPATAN SUDUT
}

\author{
Lasker P. Sinaga ${ }^{1\}}$ \\ ${ }^{1\}}$ Jurusan Matematika FMIPA, Universitas Negeri Medan \\ e-mail: lazer_integral@yahoo.com
}

\begin{abstract}
ABSTRAK
Model gerak ayunan yang dipengaruhi gaya gesekan yang berbanding lurus dengan kecepatan sudut merupakan suatu persamaan diferensial nonlinear. Model ini diubah menjadi sistem persamaan diferensial nonlinear yang lebih sederhana dan memiliki solusi bersifat periodik dengan titik kritis $P(n \pi, 0)$ dengan $n$ bilangan bulat. Titik-titik kritis akan stabil jika $n$ adalah bilangan genap dan sebaliknya, tidak stabil jika $n$ adalah bilangan ganjil. Bentuk kestabilan (simpul, pelana atau spiral) dari titik kritis bergantung pada nilai-nilai parameter model tersebut.
\end{abstract}

Kata kunci: persamaan diferensial, sistem dinamik, gerak ayunan, titik kritis, kestabilan

\begin{abstract}
The pendulum motion model influenced by friction force that is directly proportional to the angular velocity. This model is converted into a simpler nonlinear differential equation system and has a periodic solution with critical point $P(n \pi, 0)$ where $n$ is an integer. The critical points will be stable if $n$ is an even numbers and vice versa, will be unstable if $n$ is an odd number. The stability form (node, saddle or spiral) of critical points depends on the value of the model's parameter.
\end{abstract}

Key words: differential equation, dynamic system, pendulum motion, critical points, stability

\section{Pendahuluan}

Persamaan diferensial sering digunakan untuk memodelkan berbagai masalah dalam kehidupan sehari-hari ke bentuk matematis. Bentuk dan kerumitan model yang diperoleh bergantung pada karakteristik dan kerumitan masalah itu juga. Berbagai jenis persamaan diferensial dan sistem persamaan diferensial, linear atau nonlinear, homogen atau nonhomogen dapat digunakan untuk memodelkan masalah nyata $[2,4,5,6,7]$. Keadaan masalah nyata dapat dipelajari melalui proses pengamatan dan analisis pada model matematika permasalahan tersebut. Berdasarkan model matematis maka titik kritis dan 
perilaku solusi serta kestabilannya dapat ditentukan secara analitik maupun numerik $[4,5,6,7]$.

\section{Kajian Teori}

Analisis model matematis dalam system dinamika dilakukan dengan melakukan proses linearisasi pada model dan menemukan titik kritisnya serta menentukan kestabilan titik kritis tersebut $[4,5,7]$.

Definisi 1. Titik $\left(x_{0}, y_{0}\right)$ yang memenuhi sistem otonomus $\dot{x}=f(x, y)$ dan $\dot{y}=g(x, y)$ disebut titik kritis (atau titik keseimbangan) jika $f\left(x_{0}, y_{0}\right)=0$ dan $g\left(x_{0}, y_{0}\right)=0$.

Teorema 1. Titik kritis $O(0,0)$ dari sistem nonlinear $\dot{x}=a x+b y+F(x, y)$ dan $\dot{y}=c x+d y+G(x, y)$ merupakan:

a. Simpul (node) jika akar-akar persamaan karakteristik adalah bilangan real dan bertanda sama.

b. Pelana (saddle) jika akar-akar persamaan karakteristik adalah bilangan real dan berbeda tanda.

c. Pusat (fokus) jika akar-akar persamaan karakteristik adalah bilangan kompleks sekawan sejati.

d. Pusat (spiral) jika akar-akar persamaan karakteristik adalah bilangan kompleks tidak sejati.

Model Gerak ayunan yang dipengaruhi gaya gesekan yang berbanding lurus dengan kecepatan sudut dimodelkan pada [5] dengan persamaan diferensial nonlinear dengan bentuk:

$$
\frac{d^{2} \theta}{d t^{2}}+k \frac{d \theta}{d t}+\omega^{2} \sin \theta=0, k>0
$$


Selain melakukan analisis pada model, perilaku solusi model akan diamati juga dengan simulasi atau pendekatan numerik yaitu dengan menggunakan forward euler $[3,6]$. Dengan demikian simulasi numerik tersebut akan difasilitasi dengan komputer yaitu software matlab $[1,8]$.

\section{Metode Penelitian}

Penelitian ini dilakukan dengan cara studi literatur dengan berbagai dukungan definisi dan teorema dengan teknis sebagai berikut: mengubah persamaan diferensial nonlinear menjadi sistem persamaan nonlinear dan linearisasi, menemukan titik kritis dan kestabilannya, melakukan simulasi dengan pendekatan numerik (forward euler) $[3,6]$.

\section{Hasil dan Pembahasan}

Suatu ayunan bergerak dipengaruhi oleh gaya gesekan yang berbanding lurus dengan kecepatan sudut $\theta$ merupakan persamaan diferensial dengan bentuk

$$
\frac{d^{2} \theta}{d t^{2}}+k \frac{d \theta}{d t}+\omega^{2} \sin \theta=0, k>0
$$

Persamaan diferensial nonlinear (1) diubah menjadi sistem persamaan diferensial dengan memisalkan $\theta=x$ dan $\frac{d \theta}{d t}=y$, yaitu:

$$
\frac{d x}{d t}=y \text { dan } \frac{d y}{d t}+k y+\omega^{2} \sin x=0
$$

Titik kritis dari sistem persamaan (2) dapat diperoleh jika memenuhi:

$$
\frac{d x}{d t}=y=0 \text { dan } \frac{d y}{d t}=-k y-\omega^{2} \sin x=0
$$

Dengan menyelesaikan sistem (3) maka diperoleh $y=0$ dan $\sin x=0$. Mengingat fungsi trigonometri bersifat periodik maka persamaan trigonometri $\sin x=0$ menghasilkan solusi $x=n \pi$ untuk $n$ bilangan bulat. Dengan demikian, titik kritis model tersebut adalah: 
Berdasarkan sifat periodik fungsi sinus maka titik kritis yang dikaji cukup pada titik $O(0,0)$ dan $Q(\pi, 0)$.

\subsection{Analisis stabilitas titik kritis $O(0,0)$}

Dengan menggunakan deret Mclaurin pada $\sin x$ maka sistem (2) dapat dilinearkan menjadi:

$$
\frac{d x}{d t}-y=0 \text { dan } \frac{d y}{d t}+k y+\omega^{2} x=0
$$

Jika $m$ adalah akar karakteristik persamaan $\frac{d^{2} x}{d t^{2}}+k \frac{d x}{d t}+\omega^{2} x=0$ maka diperoleh persamaan karakterisitik $m^{2}+k m+\omega^{2}=0$ dengan akar-akar $m_{1,2}=\frac{-k \pm \sqrt{k^{2}-4 \omega^{2}}}{2}$. Berdasarkan nilai diskriminan $D=k^{2}-4 \omega^{2}$, akar-akar karakteristik tersebut dikaji menjadi 3 kasus, yaitu:

\subsubsection{Kasus 1 (Untuk $k<2 \omega$ )}

Jika $k<2 \omega$ maka $D<0$ sehingga akar-akar yang diperoleh adalah bilangan kompleks tak sejati yaitu $m_{1}=\frac{-k+p i}{2}$ dan $m_{2}=\frac{-k-p i}{2}$ untuk $p$ bilangan real positif. Solusi sistem persamaan adalah $x=A e^{(-k+p i) \frac{t}{2}}+B e^{(-k-p i) \frac{t}{2}}$ dan $y=C e^{(-k+p i) \frac{t}{2}}+D e^{(-k-p i) \frac{t}{2}}$. Kedua solusi bersifat periodik dan asimtotik menuju titik asal $O(0,0)$. Jika $k>0$ maka diperoleh $x \rightarrow 0$ dan $y \rightarrow 0$ untuk $t \rightarrow \infty$. Dengan demikian titik kritis ini disebut stabil (spiral) asimtotik untuk $k>0$. 


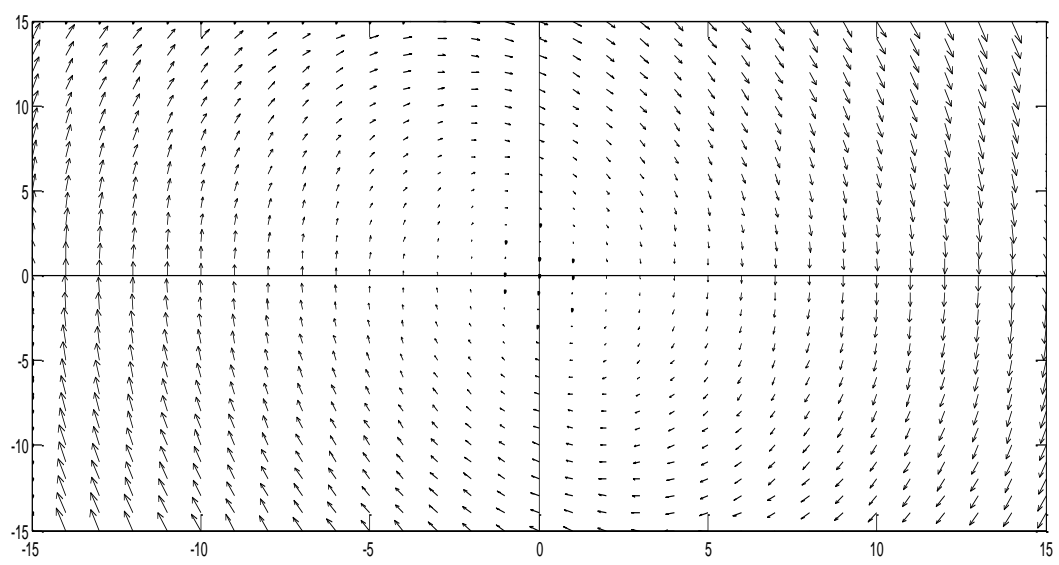

Gambar 1. Stabilitas titik kritis $\mathrm{O}(0,0)$ untuk $k<2 \omega$

4.1.2 Kasus 2. (Untuk $k=2 \omega$ )

Jika $k=2 \omega$ maka $D=0$ sehingga akar-akar yang diperoleh adalah bilangan real negatif yang sama yaitu $m_{1}=m_{2}=-\frac{k}{2} \quad$ untuk $k>0$. Solusi persamaan adalah $x=A e^{-\frac{k}{2} t}+B t e^{-\frac{k}{2} t}$ dan $y=C e^{-\frac{k}{2} t}+D t e^{-\frac{k}{2} t}$. Dengan demikian, $\frac{y}{x}=\frac{C+D t}{A+B t}$ dengan $\frac{y}{x} \rightarrow \frac{D}{B}$ untuk $t \rightarrow \infty$. Kurva bersifat asimtotik menuju titik asal $O(0,0)$ dengan gradien $\frac{D}{B}$. Jadi titik kritis ini disebut stabil simpul (node) untuk $k>0$.

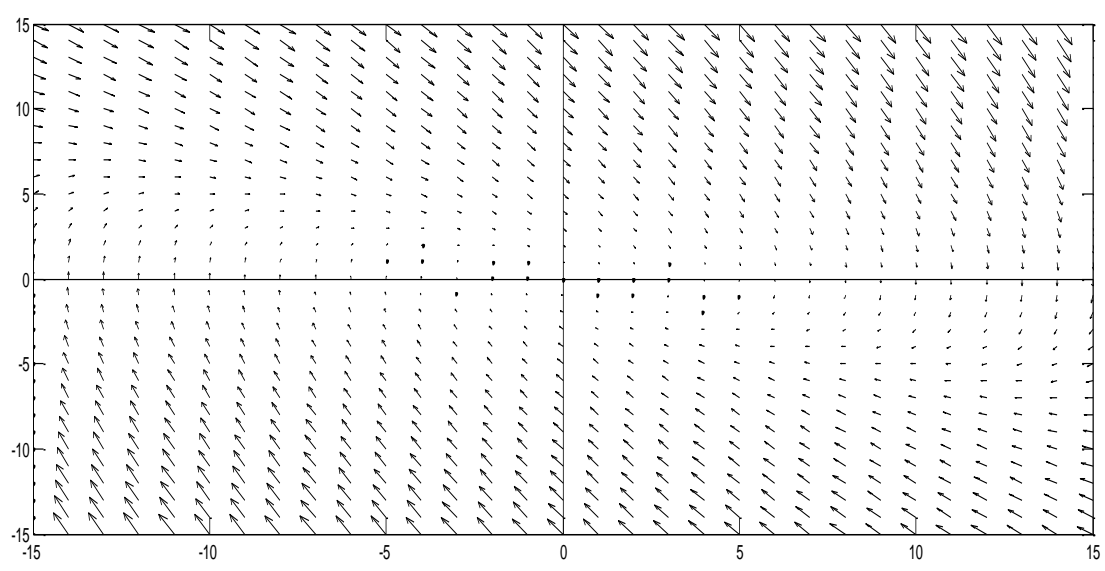

Gambar 2. Stabilitas titik kritis $\mathrm{O}(0,0)$ untuk $k=2 \omega$ 
4.1.3 Kasus 3. (Untuk $k>2 \omega$ )

Jika $k>2 \omega$ maka $D>0$ dengan $q=\sqrt{k^{2}-4 \omega^{2}}$ dan diperoleh $k>q$ sehingga akarakar karakteristik adalah bilangan real negatif yaitu $m_{1}=\frac{-k+q}{2}$ dan $m_{2}=\frac{-k-q}{2}$ untuk $q$ bilangan real positif. Solusi persamaan adalah $x=A e^{\frac{-k+q}{2} t}+B e^{\frac{-k-q}{2} t}$ dan $y=C e^{\frac{-k+q}{2} t}+D e^{\frac{-k-q}{2} t}$. Dengan demikian, titik kritis ini disebut stabil simpul (node) untuk $k>0$.

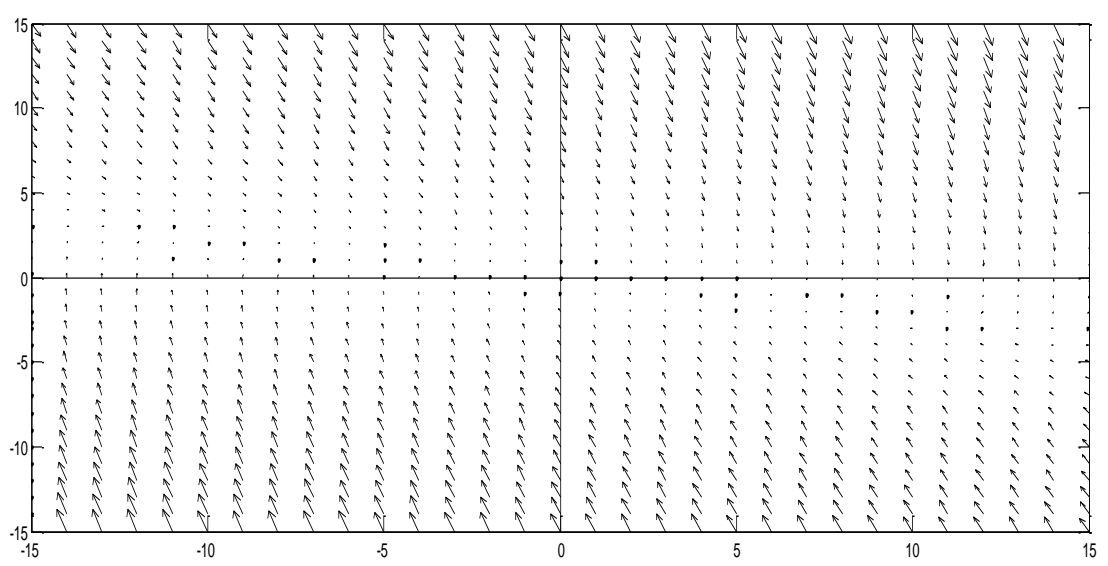

Gambar 3. Stabilitas titik kritis $\mathrm{O}(0,0)$ untuk $k>2 \omega$

\subsection{Analisis stabilitas titik kritis $Q(\pi, 0)$}

Sistem (2) dapat dilinearisasi menjadi sistem persamaan diferensial linear homogen, yaitu:

$$
\frac{d x}{d t}-y=0 \text { dan } \frac{d y}{d t}+k y-\omega^{2}(x-\pi)=0
$$

misalkan $z=x-\pi$ sehingga system persamaan menjadi:

$$
\frac{d z}{d t}-y=0 \text { dan } \frac{d z}{d t}+k z-\omega^{2} z=0
$$


Persamaan $\quad \frac{d^{2} z}{d t^{2}}+k \frac{d z}{d t}-\omega^{2} z=0 \quad$ mempunyai persamaan karakterisitik $m^{2}+k m-\omega^{2}=0$ dengan akar-akar $m_{1,2}=\frac{-k \pm \sqrt{k^{2}+4 \omega^{2}}}{2}$. Karena $k>0$ dan $\omega \neq 0$ maka akar-akar karakteristik adalah bilangan real berbeda tanda sehingga titik kritis $Q(\pi, 0)$ adalah titik pelana (saddle) dan tidak stabil.

Perhatikan gambar!

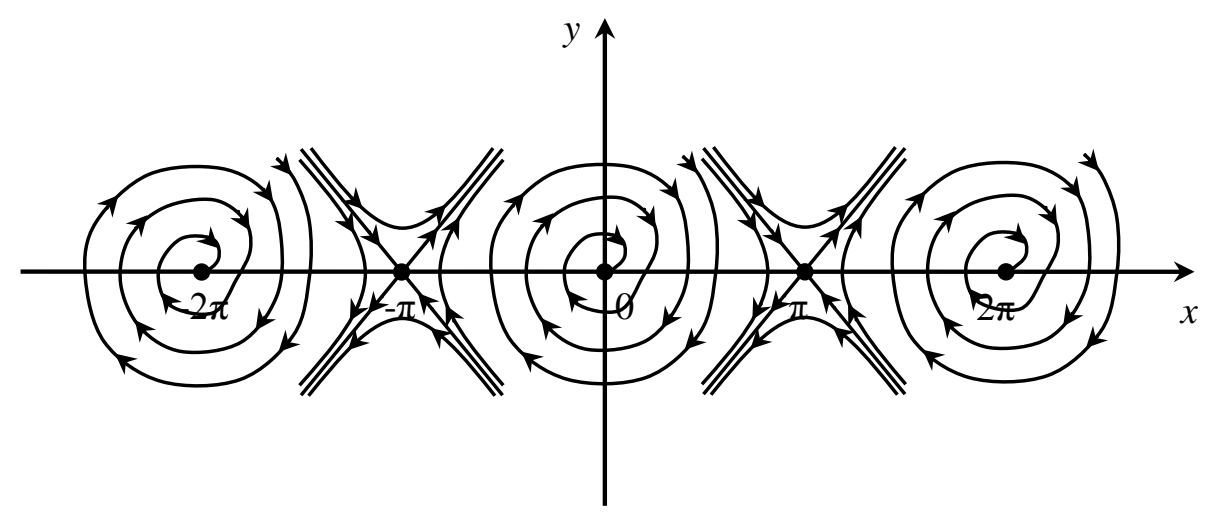

Gambar 4. Stabilitas titik kritis untuk $k<2 \omega$

Keterangan Gambar 4.

Untuk $k<2 \omega$ maka titik kritis $(n \pi, 0)$ untuk $n$ bilangan bulat genap berupa spiral dan stabil asimtotik sementara titik kritis berupa titik pelana (saddle) dan tidak stabil untuk $n$ bilangan bulat ganjil. 


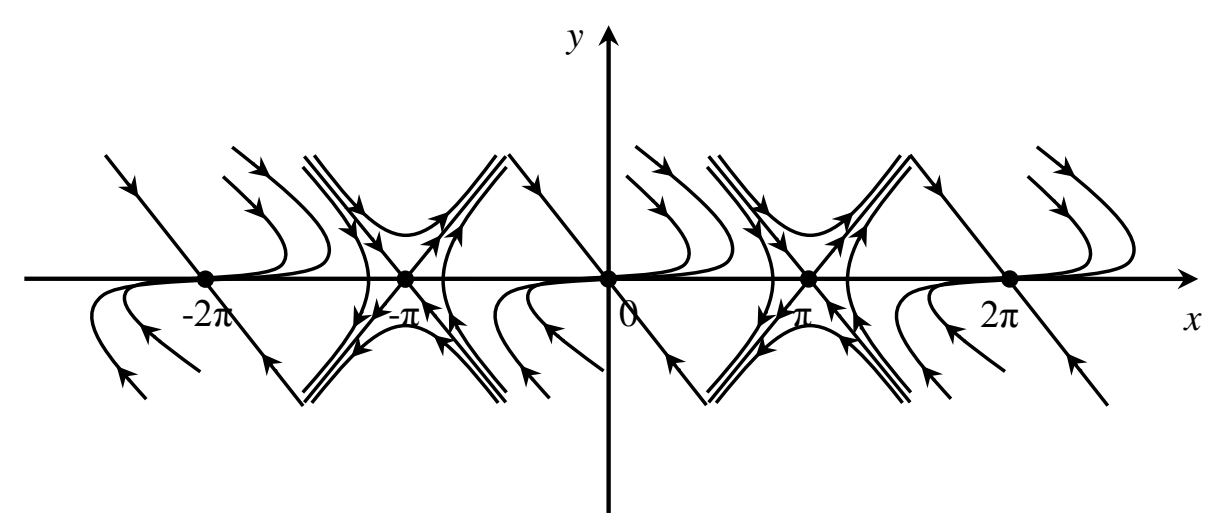

Gambar 5. Stabilitas titik kritis untuk $k \geq 2 \omega$

Keterangan Gambar 5.

Untuk $k \geq 2 \omega$ maka titik kritis $(n \pi, 0)$ untuk $n$ bilangan bulat genap berupa stabil simpul (node) sementara titik kritis berupa titik pelana (saddle) dan tidak stabil untuk $n$ bilangan bulat ganjil.

\section{Kesimpulan dan Saran}

\subsection{Kesimpulan}

Model gerakan ayunan yang dipengaruhi oleh gaya gesekan yang berbanding lurus dengan kecepatan sudut mempunyai titik kritis $(n \pi, 0)$ untuk $n$ bilangan bulat. Titik $O(0,0)$ adalah stabil asimtotik untuk $k<2 \omega$, stabil simpul untuk $k \geq 2 \omega$. Titik kritis $Q(\pi, 0)$ adalah pelana dan tak stabil. Untuk $n$ bilangan genap maka titik kritis adalah stabil dan tidak stabil untuk $n$ bilangan ganjil.

\subsection{Saran}

Penelitian ini mengkaji stabilitas dan trajektori model gerakan ayunan yang dipengaruhi oleh gaya gesekan yang berbanding lurus dengan kecepatan sudut. Perlu dikembangkan dengan menunjukkan bifurkasi pada model tersebut. 


\section{DAFTAR PUSTAKA}

[1] Arhami, M., dan Desiani, A., (2005), Pemrograman Matlab, Penerbit Andi, Yogyakarta.

[2] Edwards C. H., dan Penney D. E., 2008, Elementary Differential Equations, Pearson education, Inc, Upper saddle River, New Jersey.

[3] Heri, S., dan Dewi, R., (2005), Metode Numerik dengan Pendekatan Algoritma, SinarBaru Agensindo, Bandung.

[4] Perko, L., (2001), Differential Equations and Dynamical Systems, Springer, New York.

[5] Santoso W., 1982, Persamaan Diferensial Biasa dengan penerapan Modern, Erlangga.

[6] Simmons G. F., dan Krantz S. G., 2007, Differential Equations: theory, technique, and practice, McGraw-Hill Companies, Inc, New York.

[7] Tenenbaum M., dan Pollard H., 1963, Ordinary Differential Equations, Harver \& Row Publishers, Inc, New York.

[8] Widiarsono, T., (2005), Tutorial Praktis Belajar Matlab, Jakarta. 